\title{
Synthesis and Characterization of a Nanocomposite Containing a Copper-Based MOF and Nickel Ferrite ${ }^{+}$
}

\author{
Maryam Haddadi and Faranak Manteghi * \\ Department of Chemistry, Iran University of Science and Technology, Tehran 1684613114, Iran; \\ * Correspondence: f_manteghi@iust.ac.ir \\ + Presented at the 24th International Electronic Conference on Synthetic Organic Chemistry, 15 November- \\ 15 December 2020; Available online: https://ecsoc-24.sciforum.net/.
}

Received: date; Accepted: date; Published: date

\begin{abstract}
In this research, a nanocomposite of copper-based MOF and nickel ferrite has been synthesized, using layer by layer method. The obtained $\mathrm{NiFe}_{2} \mathrm{O}_{4} @$ HKUST-1 was characterized by XRD, FTIR and FESEM. The results showed that the nanocomposite has a core-shell structure in which $\mathrm{NiFe}_{2} \mathrm{O}_{4}$ is the core and HKUST-1 acts as the shell.
\end{abstract}

Keywords: MOF; Composite; HKUST-1; Nickel ferrite; core-shell

\section{Introduction}

Recently, Metal-organic frameworks (MOFs) have been developed rapidly as a new class of functional inorganic-organic hybrid materials. They are crystalline microporous materials which include metals at the center and organic ligands as linkers. The ligands create an open porous threedimensional structure. MOFs have particular properties like high pore volume and surface area, unsaturated metal sites, textural properties and so on. With these properties we can use them in many applications including separation, photocatalysis, gas storage, adsorption, electrochemistry, fluorescence, sensing and so on [1].

There are many methods to synthesize MOF, such as hydrothermal/solvothermal, microwave, electrochemical. Among them, hydrothermal technique is used more than other methods.

HKUST-1, is a copper-based MOF characterized by a 3D system of square-shaped pore, that draws a great attention owning to it can be synthesized with commercially available reagents and has high surface area, accessible coordinatively unsaturated sites (CUS) and high chemical stability.

On the other hand, the post-synthesis modifications (PSMs) of MOF have been demonstrated to be a crucial strategy for advanced functions. In particular, the incorporation of magnetic nanoparticles (especially nanocrystalline spinel ferrites with the common formula $\mathrm{MFe}_{2} \mathrm{O}_{4}(\mathrm{M}=\mathrm{Ni}$, $\mathrm{Zn}, \mathrm{Mn}, \mathrm{Co}, \mathrm{Mg}$, etc.) into MOFs has been investigated because the product of nanocomposites can be transferred via an external magnetic field. This function is very significant in the adsorption of heavy metal ions or dyes or it can be utilized for drug delivery or magnetic resonance imaging [2].

Nickel ferrite powder, is one of the very important ferrite materials that has been considered for many applications such as high density magnetic storage media, MRI contrast agents, and so on [3].

In this research, a nanocomposite of $\mathrm{NiFe}_{2} \mathrm{O}_{4} @ \mathrm{HKUST}-1$ with core-shell structure was prepared and characterized by X-ray diffraction (XRD), Fourier transform infrared spectroscopy (FT-IR) and Field Emission Scanning Electron Microscopy (FESEM) methods. 


\section{Experimental}

\subsection{Chemicals and Materials}

The materials that used in this study including $\mathrm{Cu}\left(\mathrm{NO}_{3}\right)_{2} \cdot 3 \mathrm{H}_{2} \mathrm{O}$ (copper nitrate trihydrated), $\mathrm{BTCH}_{3}$ (trimesinic acid), $\mathrm{FeCl}_{3}$ (iron (III) chloride), $\mathrm{NiCl}_{2}$ (nickel chloride), $\mathrm{CH}_{3} \mathrm{COONa}$ (sodium acetate), $\mathrm{C}_{2} \mathrm{H}_{4} \mathrm{O}_{2} \mathrm{~S}$ (mercaptoacetic acid), $\mathrm{C}_{2} \mathrm{H}_{6} \mathrm{O}_{2}$ (ethylene glycol) and $\mathrm{C}_{2} \mathrm{H}_{5} \mathrm{OH}$ (ethanol). All these materials were prepared from Merck (Germany) and used without further purification.

\subsection{Instrumentation and measurements}

The phase characterization of $\mathrm{NiFe}_{2} \mathrm{O}_{4} @$ HKUST- 1 were performed by XRD in the $2 \theta$ limited range of $10^{\circ}-90^{\circ}$ (Shimadzu, Japan), FTIR spectra was taken with Shimadzu (IR solution) 8400 s to recognize the functional groups, and morphological verification was performed by FESEM (Tescan. Mira3).

\subsection{Methods}

\subsubsection{Synthesis of HKUST-1}

This MOF was synthesized with one-step solvothermal technique. In summary, separate solutions of $\mathrm{Cu}\left(\mathrm{NO}_{3}\right)_{2} \cdot 3 \mathrm{H}_{2} \mathrm{O}$ and $\mathrm{BTCH}_{3}$ were dissolved in deionized water and ethanol, respectively. Then the two solutions combined with each other and sonicated. The obtained solution was then heated at $115^{\circ}$ in an autoclave. After cooling down and colleting its precipitate by centrifugation, it was washed with ethanol and deionized water for several times and dried in a vacuum oven.

\subsubsection{Synthesis of $\mathrm{NiFe}_{2} \mathrm{O}_{4}$}

$\mathrm{NiFe}_{2} \mathrm{O}_{4}$ as a core was prepared as follows. $\mathrm{FeCl}_{3}, \mathrm{NiCl}_{2}$ and sodium acetate were dissolved in ethylene glycol, and sonicated for better dissolution. Then it was transferred to the autoclave and heated to $190^{\circ}$. After cooling down, it was rinsed with ethanol and deionized water several times and dried in a vacuum oven.

\subsubsection{Synthesis of $\mathrm{NiFe}_{2} \mathrm{O}_{4} @ \mathrm{HKUST}-1$}

The core-shell composite was prepared with layer-by layer assembly technique. At first, mercaptoacetic acid was dissolved in ethanol, then added to $\mathrm{NiFe}_{2} \mathrm{O}_{4}$ solution. After a while, the modified form of the latter was separated with a magnet and washed with ethanol and distilled water. The dried powder of $\mathrm{NiFe}_{2} \mathrm{O}_{4}$ with $\mathrm{Cu}\left(\mathrm{NO}_{3}\right)_{2} \cdot 3 \mathrm{H}_{2} \mathrm{O}$ were mixed in ethanol, heated and stirred. The mix was separated by magnet and added to ethanolic solution of $\mathrm{BTCH}_{3}$, heated and sttired, then the product was magnetically separated, washed and dried at $50^{\circ} \mathrm{C}$. This procedure was repeated in 10 cycles.

\section{Results:}

\subsection{XRD Patterns}

The X-ray diffraction of $\mathrm{NiFe}_{2} \mathrm{O}_{4}, \mathrm{HKUST}-1$, and $\mathrm{NiFe}_{2} \mathrm{O}_{4} @ \mathrm{HKUST}-1$ were displayed in Figure 1. As can be seen, $\mathrm{NiFe}_{2} \mathrm{O}_{4} @ \mathrm{HKUST}-1$ demonstrated the prosperous synthesis of the new nanocomposite. 


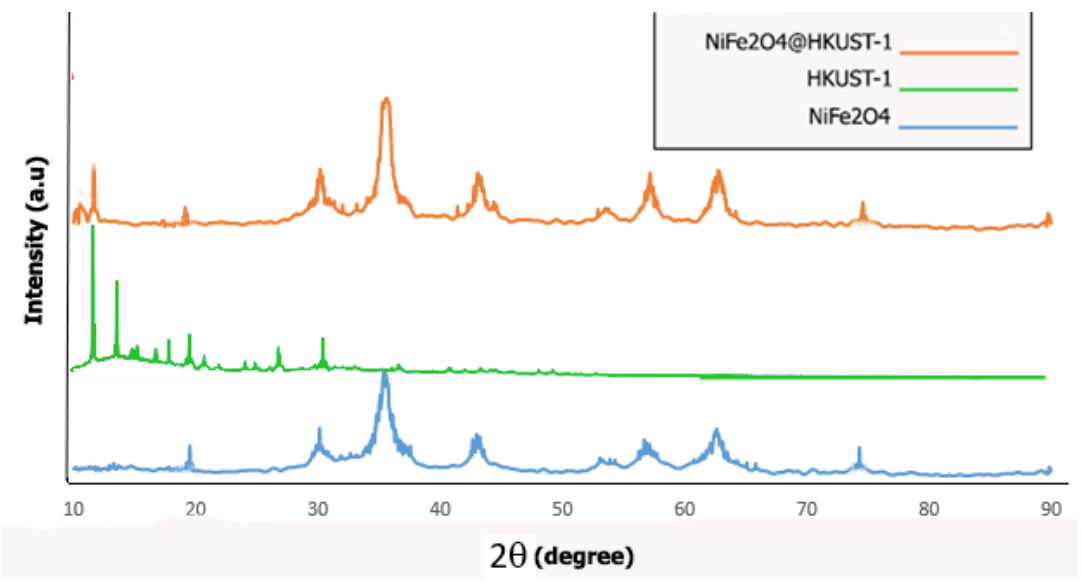

Figure 1. XRD patterns of $\mathrm{NiFe}_{2} \mathrm{O}_{4}$, HKUST-1, and $\mathrm{NiFe}_{2} \mathrm{O}_{4} @ \mathrm{HKUST}-1$.

\subsection{FTIR Spectra}

In the FT-IR spectra shown in Figure 2, HKUST-1 spectrum, the band at $1372 \mathrm{~cm}^{-1}$ defined to C$\mathrm{O}$, the bands at 1450 and $1560 \mathrm{~cm}^{-1}$ defined to $\mathrm{C}=\mathrm{O}$ of BTC ligand. The band at $1642 \mathrm{~cm}^{-1}$ resulted from $\mathrm{C}=\mathrm{C}$ in aromatic ring, and at $1715 \mathrm{~cm}^{-1}$ was ascribed to $\mathrm{COO}^{-}$in BTC. In the other hand, about spectra of $\mathrm{NiFe}_{2} \mathrm{O}_{4}$ and $\mathrm{NiFe}_{2} \mathrm{O}_{4} @ \mathrm{HKUST}-1$ the band around $550 \mathrm{~cm}^{-1}$ was matched with bond of Ni$\mathrm{O}$ and Fe-O. The bands at 485, 670, $808 \mathrm{~cm}^{-1}$ were specified to deformation vibration of $\mathrm{Fe}-\mathrm{OH}$ groups. The wide band around $3400 \mathrm{~cm}^{-1}$ could be matched to $\mathrm{O}-\mathrm{H}$ stretching vibration of $\mathrm{H}_{2} \mathrm{O}$ that absorbed by sample or $\mathrm{O}-\mathrm{H}$ on the surface.

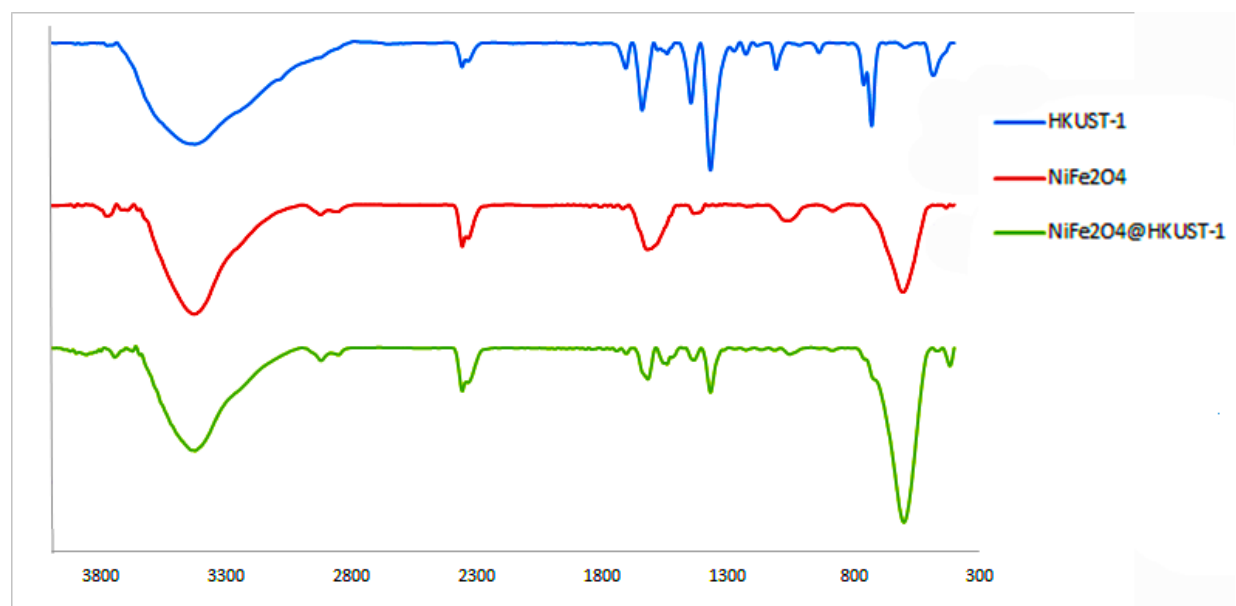

Figure 2. FTIR spectra of $\mathrm{NiFe}_{2} \mathrm{O}_{4}$, HKUST-1, and $\mathrm{NiFe}_{2} \mathrm{O}_{4} @ \mathrm{HKUST}-1$.

\subsection{FESEM Images}

The morphology of HKUST was determined with SEM image and about $\mathrm{NiFe}_{2} \mathrm{O}_{4}$ and $\mathrm{NiFe}_{2} \mathrm{O}_{4} @$ HKUST-1 were distinguished with FESEM images. As you can observe in Figure 3 in part (a), HKUST-1 has octahedral structure with sharp edge. In part b and c you can see that $\mathrm{NiFe}_{2} \mathrm{O}_{4}$ and $\mathrm{NiFe}_{2} \mathrm{O}_{4} @$ HKUST- 1 are spheres and $\mathrm{NiFe}_{2} \mathrm{O}_{4}$ as a core was encapsulated with HKUST-1 as a shell. 

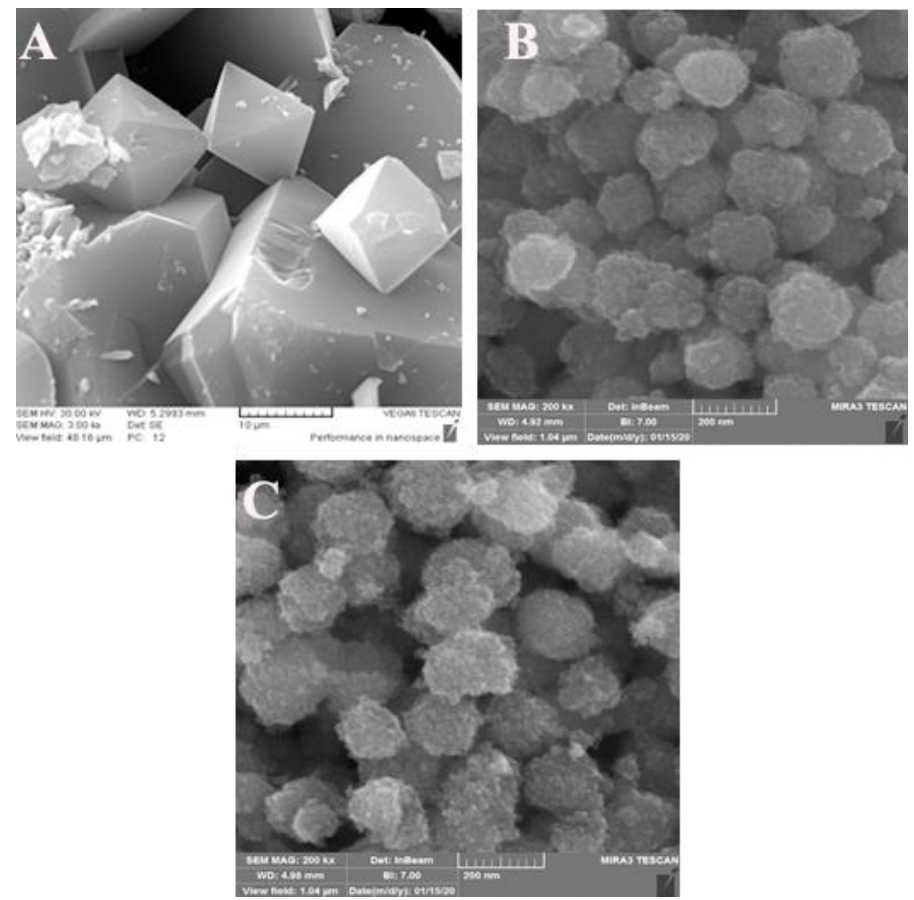

Figure 3. SEM image of (A) HKUST-1, (B) $\mathrm{NiFe}_{2} \mathrm{O}_{4}$ and (C) $\mathrm{NiFe}_{2} \mathrm{O}_{4} @ \mathrm{HKUST}-1$.

\section{Conclusion}

In this research, a new nanocomposite was synthesized with core-shell structure. Due to the results of XRD, FT-IR and FESEM analyzes, the structure was successfully formed and can be used in many applications.

\section{References}

1. Bordiga, S.; Regli, L.; Bonino, F.; Groppo, E.; Lamberti, C.; Xiao, B.; Wheatley, P.; Morris, R.; Zecchina, A. Adsorption properties of HKUST-1 toward hydrogen and other small molecules monitored by IR. Phys. Chem. Chem. Phys. 2007, 9, 2676-2685.

2. Srivastava, M.; Ojha, A.K.; Chaubey, S.; Materny, A. Synthesis and optical characterization of nanocrystalline $\mathrm{NiFe} 2 \mathrm{O} 4$ structures. J. Alloys Compd. 2009, 481, 515-519.

3. Sivakumar, P; Ramesh, R.; Ramanand, A.; Ponnusamy, S.; Muthamizhchelvan, C. Synthesis and characterization of nickel ferrite magnetic nanoparticles. Mater. Res. Bull. 2011, 46, 2208-2211.

Publisher's Note: MDPI stays neutral with regard to jurisdictional claims in published maps and institutional affiliations.

() 2020 by the authors. Submitted for possible open access publication under the terms and conditions of the Creative Commons Attribution (CC BY) license (http://creativecommons.org/licenses/by/4.0/). 